\title{
An experience with the Global Trigger Tool for the study of adverse events in a medical ward
}

\author{
Uma experiência com a Global Trigger Tool no estudo dos eventos adversos \\ num serviço de medicina \\ Una experiencia con la Global Trigger Tool en el estudio de eventos adversos \\ en un servicio de medicina
}

Ludmila Pierdevara*; Inês Margarida Ventura**; Margarida Eiras***;

Amélia Maria Brito Gracias****; Carina Soares da Silva*****

\begin{abstract}
Background: Health care provision is associated with adverse events (AEs) which harm hospitalized patients.

Objectives: To study AEs in a medical ward.

Methodology: A quantitative, descriptive, observational and retrospective study was conducted from 1 September 2014 to 31 December 2014 in a medical ward of the Algarve Hospital Center. The instrument used to identify the AEs was the Global Trigger Tool (GTT). All the patients who were discharged between 1 January 2014 and 30 September 2014 were listed.

Results: The interrater agreement concerning the AE classification, using the Kappa value, proved to be perfect. A total of 278 triggers were identified, of which 124 resulted in AEs: 44.6\% of AEs occurred during the hospitalization, and 9.4\% of the patients presented AEs at the moment of admission. We found a total of $62.63 \mathrm{AEs}$ per 1,000 patient days, $137.8 \mathrm{AE}$ per 100 admissions, and one $\mathrm{AE}$ in $31.1 \%$ of the cases during hospitalization.

Conclusion: The GGT proved to be a useful tool to analyze AEs in hospital settings.
\end{abstract}

Keywords: patient safety; safety management; patient harm; medical errors

\section{Resumo}

Enquadramento: A prestação de cuidados de saúde está associada aos eventos adversos (EA) que causam dano nos doentes internados em hospitais.

Objetivos: Estudar os EA num serviço de Medicina.

Metodologia: Realizou-se um estudo quantitativo, descritivo observacional retrospetivo, de 1 de setembro a 31 de dezembro de 2014 num serviço de medicina do Centro Hospitalar do Algarve. Para identificar os EA utilizou-se a Global Trigger Tool (GTT). Listaram-se os doentes que tiveram alta hospitalar no período de 1 de janeiro a 30 de setembro do ano 2014.

Resultados: A concordância entre as revisoras, relativamente à classificação dos EA, através do índice de Kappa, demonstrou ser perfeita. Identificaram-se 278 triggers, dos quais 124 resultaram em EA, 44,6\% dos EA ocorreram durante o internamento e 9,4\% dos doentes apresentavam EA no momento de admissão. Constataram-se 62,63 EA por 1000 doentes dia, 137,8 EA por 100 admissões e, em 31,1\% dos casos, ocorreu um EA durante $\mathrm{o}$ internamento.

Conclusão: A metodologia GTT é uma ferramenta útil no estudo dos EA no contexto hospitalar.

Palavras-chave: segurança do paciente; gestão da segurança; dano ao paciente; erros médicos

\footnotetext{
*MSc, RN, Algarve Hospital Center, 8600-524, Lagos, Portugal [pierdevara@ hotmail.com]. Contribution to the article: article writing, principal investigator. Address for correspondence: Praça do Poder Local Lote 7A; $6^{\circ}$ frente, $8500-045$ Portimão, Portugal.

** RN, Algarve Hospital Center, 8600-371, Lagos, Portugal [ines.mrventura@gmail.com]. Contribution to

the article: data collection.
**** Ph.D., Professor, Lisbon School of Health Technology, 1990-096, Lisboa, Portugal [margarida.eiras@ estesl.ipl.pt]. Contribution to the article: data analysis and discussion.

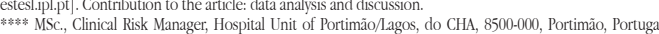
[gracias.amelia@gmail.com!. Contribution to the article: data collection.

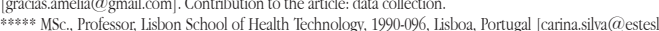
ipl.pt]. Contribution to the article: statistical analysis.
}

\section{Resumen}

Marco contextual: La prestación de cuidados de salud está asociada a los eventos adversos (EA) que causan daño a los pacientes ingresados en hospitales.

Objetivos: Estudiar los EA en un servicio de medicina.

Metodología: Se realizó un estudio cuantitativo, descriptivo y observacional retrospectivo, del 1 de septiembre al 31 de diciembre de 2014 en un servicio de medicina del Centro Hospitalario del Algarve. Para identificar los EA se utilizó la metodología GTT (Global Trigger Tool). Se realizó un listado de los pacientes a los que se les dio el alta hospitalaria en el periodo del 1 de enero al 30 de septiembre del año 2014. Resultados: La concordancia entre las revisoras en relación a la clasificación de los EA a través del índice de Kappa demostró que era perfecta. Se identificaron 278 desencadenantes, de los cuales 124 dieron como resultado EA; el 44,6 \% de los EA ocurrió durante la hospitalización y el 9,4\% de los pacientes presentaban EA al ingresar en el hospital. Se constataron 62,63 EA por 1000 pacientes/día, 137,8 EA por 100 ingresos y en el 31,1\% de los casos hubo un EA durante la hospitalización.

Conclusión: La metodología GGT es una herramienta útil en el estudio de los EA en el contexto hospitalario.

Palabras clave: seguridad del paciente, gestión de seguridad, daño del paciente; errores médicos

Received for publication: 03.12 .15

Accepted for publication: 02.05 .16 


\section{Introduction}

The issue of patient safety (PS) is currently expanding worldwide, addressing various aspects in the different health systems, as mentioned in the nine strategic goals of the Portuguese National Plan for Patient Safety 2015-2020 (Despacho $\mathrm{n}^{\mathrm{O}}$ 1400-A/2015). Its eighth objective should be highlighted: "To ensure the systematic practice of report, analysis and prevention of incidents", which aims to increase by $20 \%$ the reporting of safety incidents per year until 2020.

PS focuses on the maintenance of the provision of safe care involving a series of organizational processes of identification, management and prevention of incidents and adverse events (Tingle, 2011).

The consequences of $\mathrm{AE}$ affect patients directly, causing physical, moral and property damages and suffering, representing high costs for the health sector, which must be controlled and minimized within the current economic crisis and lack of resources (Observatório Português dos Sistemas de Saúde [OPSS], 2015).

In the European Union, $8 \%$ to $12 \%$ of patients admitted to hospitals suffer AEs. In Portugal, as in other countries, the incidence rate of AEs is $11.1 \%$, which can prolong hospital length-of-stay to up to 11 days (Sousa, Uva, Serranheira, Leite, \& Nunes, 2011). According to the Institute for Healthcare Improvement (IHI), the traditional methods currently used to identify AEs are mainly focused on voluntary reporting, which makes this process dependent of the reporter (IHI, 2009). On the other hand, the scientific evidence shows that only $10 \%$ to $20 \%$ of errors are reported and that $90 \%$ to $95 \%$ of these cause no harm to the patient.

In Portugal, the Directorate-General for Health (DGS), by proposal of the Department of Quality in Health and within the scope of organizational quality, issued the norm entitled National System for Notification of Incidents (Sistema Nacional de Notificação de Incidentes - NOTIFICA (SNNIAE)), in which health care providers are encouraged to report AEs and incidents in an anonymous and confidential way so to allow the services to correct the causes and prevent them from happening again (Direcção-Geral da Saúde, 2014). However, the OPSS, in the 2015 Spring Report, mentions that the DGS, while monitoring the SNNIAE/2013, found that professionals only reported 244 incidents during a 1-year period: $23 \%$ were associated with patient incidents, 19\% with the professionals' behavior, and 17\% with administrative procedures.

Therefore, this system can be an important tool, provided that AEs are indeed reported and analyzed. However, the evidence shows that health professionals do not report most of the incidents (Pfeiffer, Manser, \& Wehner, 2010) and, consequently, the number of errors identified is much lower than the number of errors that actually happened. The main reason for this is the apportionment of blame associated with the errors, preventing the reporting of most of them. Based on the identification of a highly important problematic area for health care provision, we considered it appropriate to study the AEs in a medical ward, establishing the following specific objectives: to identify and classify the AEs in a medical ward of the Algarve Hospital Center (AHC); to identify the number of AEs per 1,000 patient days; to identify the number of AEs per 100 admissions; and to identify the number of AEs per category of harm.

\section{Background}

According to the World Health Organization (WHO), an $\mathrm{AE}$ is an event or circumstance that could have resulted in unnecessary harm to a patient. Harm implies the impairment of a body structure or function or any deleterious effect arising thereof, including disease, injury, suffering, disability or death, and can occur at the physical, social or psychological level (Direcção-Geral da Saúde, 2011).

AEs can be detected in different ways, being considered a key step toward improving the safety of health care provision.

In recent years, several methods have been used for reporting AEs: voluntary methods (incident reporting, prompted spontaneous reporting), involuntary methods (chart review, observation, patient interviews) or mixed methods (Murff, Patel, Hripcsak, \& Bates, 2003).

These methods have been shown to have a series of limitations, especially related to resource constraints (Rosen \& Mull, 2016). With the recent use of electronic clinical files, the identification of AEs was facilitated. However, according to Murff et al. (2003), the systems used for detecting errors and AEs are often ineffective solutions. With the purpose of providing the health institutions with a new tool to assess PS, the IHI 
developed, in 2000, the Global Trigger Tool (GTT) method, which is used to detect AEs. This tool has proven to have very interesting characteristics and properties, adding two modalities that complement each other: automated surveillance and review of patient records. After the conference held in 2008, supported by the Agency for Healthcare Research and Quality, where the importance of the use of triggers in the identification of AEs was discussed and unanimously accepted as a useful tool, many AEs have been identified in areas such as diagnostic errors, medication, hospital infections, surgery (Classen, 2009). As major conclusions of this conference, we highlight the need to ensure the validity and reliability of the tool, and also the environment of health care provision, since the GTT is more reliable in an inpatient setting than in outpatient setting, since the former is associated with a series of variables that involve ambiguity and subjectivity.

The incidence of AEs was assessed by Classen et al. (2011) through three different methods (GTT, voluntary reporting system and a triage tool of the Agency for Healthcare Research and Quality) applied in three hospitals of North Carolina. The GTT showed a higher reliability in the identification of AEs in.

In Sweden, Rutberg et al. (2014) conducted an observational retrospective study to identify and compare the incidence of AEs, using two methods: the GTT and the voluntary reporting system. The authors concluded that the GTT allows identifying a higher number of AEs than the voluntary reporting system, and that health institutions should use a set of useful tools to identify AEs in order to substantially reduce the costs related to the prevention of AEs.

In the same line, the studies of Ganachari, Wadhwa, Walli, Khoda, and Aggarwal (2013) and of Hwang, Chin, and Chang (2014) applied the GTT tool with the purpose of identifying AEs. These authors also concluded that the GTT surpasses traditional methods in the identification of AEs and suggest its application in future studies.

Thus, considering that the GTT is useful to analyze AEs in hospital settings, we thought that it would be important to analyze if the patient's length-of-stay and age could influence the number of AEs.

\section{Research questions}

Is there a relationship between the patients' lengthof-stay and the number of AEs?

Is there a relationship between the patients' age and the likelihood of occurrence of AEs?

\section{Methodology}

A descriptive, observational retrospective study, with a quantitative approach, was conducted at a medical ward of the Algarve Hospital Center (AHC). Data were collected between 1 September and 31 December 2014. Data were collected through the application of the GTT trigger worksheet (IHI, 2009). This version was translated and adapted to the Portuguese context by the Portuguese Association of Hospital Development (APDH), validated and tested within the scope of the training session Trigger Tool for adverse events: a team tool, organized in the southern, central and northern regions of Portugal, between March and June 2014, which is pending validation in the academic context. The GTT contains six modules which integrate multiple triggers related to different services/ departments: general care, surgery, intensive care, medication, perinatal, and emergency. Four of the modules are designed to reflect the AEs that usually occur in specific units. The modules of general care and medication are designed to reflect the AEs that may occur in any hospital unit, allowing for the identification of certain AEs such as the prescription or abrupt discontinuation of certain medications, the prescription of antidotes, the laboratory parameters and information about the patient's care and clinical evolution. Data collection was conducted according to the process described by IHI, in its publication $I H I$ Global Trigger Tool for Measuring Adverse Events IHI. The immediate objective of the GTT is to identify harm and not to determine the possibility of prevention of the event. For the classification of the harm resulting from the event, the tool uses five categories of harm in accordance with the scale of the National Coordinating Council for Medication Error Reporting and Prevention: temporary harm, required intervention (E); temporary harm, required prolonged hospitalization (F); permanent harm $(G)$; harm, required intervention necessary to sustain life $(\mathrm{H})$ and patient's death (I). The data collection 
procedures suggested by the IHI were once again applied (IHI, 2009).

Data collection took place at every 15 days (two readings per month, in a total of 9 readings). We created a list with the patients who were discharged from the hospital in each month, between 1 January and 30 September 2014. Of the total number of discharges per month, random samples of 12 processes were produced and selected using the Open Epi software.

The primary review was performed by two independent nurses, one of them being the principal investigator. The degree of agreement between the results obtained was assessed using the Kappa value, and the significance level was set at 5\% ( $p \leq .05)$. Each file was analyzed for a maximum of 20 minutes. On a monthly basis, discrepancies were identified by comparing the results and reaching a consensus regarding the AEs identified and classified, and following the grid of discriminatory analysis of the triggers. The primary reviewers met with the physician reviewer (secondary reviewer/referee), with the purpose of authenticating the review and adjusting the weighting of the primary reviews, whenever necessary.

In order to protect the confidentiality of the information, the numbers of the clinical records were coded. Although 12 cases were selected, the sample was composed of 10 cases, according to the IHI (2009), so as to ensure the non-fulfilment of the inclusion and exclusion criteria (complete clinical records, with a summary of the clinical and nursing discharge, belonging to patients who had been clinically discharged, at least, 2 months earlier, and hospital length-of-stay of more than 24 hours). The clinical records of patients aged less than 18 years were excluded, as well as those of situations in which the inpatient's main diagnosis was a psychiatric disorder and those in which the records were difficult to read.

As variables of the study, we considered the triggers integrated in the GTT, plus gender, age, total length of stay and episodes of hospitalization, and number of AEs.
Data were analyzed and processed using the statistical software SPSS (Statistical Package for the Social Sciences), version 22. The results were described using descriptive statistics, namely the distribution of frequencies (relative and absolute), measures of central tendency (mean) and measures of dispersion (standard deviation). Pearson's correlation test $(r-p)$ was applied to check for the correlation between the numerical variables: number of AEs, total length of stay and age, with a confidence interval of $95 \%$.

The ethical procedures were met. A written request was sent to the AHC administration requesting permission to conduct and publish the study, which was approved. Data confidentiality and anonymity were ensured.

\section{Results}

Of the 751 clinical discharges, we used a random sample of 90 clinical records. As regards the sociodemographic characteristics of the sample, we emphasize that the sample was evenly distributed by gender (50\%), with a mean age of 78.54 years (45-96 years) and a standard deviation of 11.88 years.

Regarding the number of hospitalizations, and although the sample was composed of 90 patients, we found a total of 138 hospitalizations, with a minimum of 1 and a maximum of 6 hospitalizations per patient, with an average of 1.56 .

Most patients were admitted to internal medicine wards, in the acute phase of disease or waiting for social resolution. The total length of stay was 1980 days, with a minimum of 2 and a maximum of 92 days per hospitalization, with a mean hospital stay of 22 days and a standard deviation of 19.2 days.

As regards the absolute number of triggers, we identified 278 triggers in 90 records. Data in Table 1 concerning the number of triggers identified shows that the most common triggers are healthcare-associated infections, pressure ulcers, readmission within 30 days, restraint use, in-hospital stroke, and any procedure complication. Due to the inpatients' profile in this ward, most triggers belong to the GTT modules related to general care and medication. 
Table 1

Distribution of the triggers identified according to classes, modules and respective categories

\begin{tabular}{|c|c|c|}
\hline Category & Classes of triggers & $n$ \\
\hline & Module A-General care & \\
\hline $\mathrm{C} 1$ & Transfusion of blood or use of blood products & 15 \\
\hline $\mathrm{C} 2$ & Code, cardiac or pulmonary arrest, or rapid Response Team activation & 1 \\
\hline $\mathrm{C} 4$ & Positive blood culture & 14 \\
\hline $\mathrm{C} 5$ & X-Ray or doppler studies for emboli or deep vein thrombosis & 5 \\
\hline C6 & Decrease in hemoglobin or hematocrit of $25 \%$ or greater & 16 \\
\hline $\mathrm{C} 7$ & Patient fall & 6 \\
\hline $\mathrm{C} 8$ & Pressure ulcers & 20 \\
\hline C9 & Readmission within 30 days & 25 \\
\hline $\mathrm{C} 10$ & Restraint use & 25 \\
\hline C11 & Healthcare-associated infections & 33 \\
\hline C12 & In-hospital stroke & 21 \\
\hline $\mathrm{C} 13$ & Transfer to higher level of care & 9 \\
\hline \multirow[t]{2}{*}{ C14 } & Any procedure complication & 20 \\
\hline & Module B - Surgery & \\
\hline S1 & Return to surgery & 2 \\
\hline S10 & Injury, repair, or removal of organ during operative procedure & 1 \\
\hline \multirow[t]{2}{*}{ S11 } & Occurrence of any operative complication & 1 \\
\hline & Module C - Medication & \\
\hline M1 & Clostridium difficile - positive stool & 6 \\
\hline M4 & Glucose less than $50 \mathrm{mg} / \mathrm{dl}$ & 3 \\
\hline M5 & Rising BUN or serum creatinine two times (2x) over baseline & 19 \\
\hline M6 & Vitamin $\mathrm{K}$ administration & 3 \\
\hline M8 & Flumazenil administration & 5 \\
\hline M10 & Anti-emetic administration & 5 \\
\hline \multirow[t]{2}{*}{ M12 } & Abrupt medication stop & 2 \\
\hline & Module D - Intensive Care & \\
\hline I1 & Pneumonia onset & 3 \\
\hline $\mathrm{I} 2$ & Readmission to the intensive care unit & 2 \\
\hline $\mathrm{I} 3$ & In-unit procedure & 6 \\
\hline \multirow[t]{2}{*}{ I4 } & Intubation/reintubation & 2 \\
\hline & Module F - Emergency Department (ED) & \\
\hline E1 & Readmission to the ED within 48 hours & 8 \\
\hline Total & & 278 \\
\hline
\end{tabular}

The data collected on bealthcare-associated and complications in order to understand the most infections and any procedure complication allowed common situations (Table 2).

us to identify and analyze several types of infections 
Table 2

Type of healthcare-associated infections and procedure complications identified and corresponding categories

\begin{tabular}{lcc}
\hline Types of infections and complications & $n(\%)$ & Category \\
\hline Healthcare-associated pneumonia & $7(7.8 \%)$ & $\mathrm{F}$ \\
Escherichia coli or pseudomonas in urine /blood & $15(16.5 \%)$ & $\mathrm{F}$ \\
Candida Parapsilosis and Klebsiella in Urine & $6(6.7 \%)$ & $\mathrm{E}$ \\
MRSA in urine, urethral exudate and sputum & $6(6.7 \%)$ & $\mathrm{F}$ \\
Infection of puncture site / phlebitis & $4(4.4 \%)$ & $\mathrm{E}$ \\
Allergic reaction, with known clinical history & $4(4.4 \%)$ & $\mathrm{E}$ \\
Urinary tract infection & $3(3.3 \%)$ & $\mathrm{F}$ \\
Sepsis & $7(7.8 \%)$ & $\mathrm{I}(n=2)$ \\
& & $\mathrm{F}(n=5)$ \\
Aspiration pneumonia & $6(6.7 \%)$ & $\mathrm{I}(n=4)$ \\
\end{tabular}

Of the total number of the triggers identified, and after the consensus of the research team, $44.6 \%(n$ $=124)$ were considered AEs during hospitalization, and $9.4 \%(n=25)$ were considered AEs at hospital admission. The interrater agreement concerning the classification of AEs, using the Kappa value, with a level of significance of $5 \%$, ranged between 0.841 and 0.935 in AEs occurring during hospitalization and 0.992 and 1.000 at admission.

Regarding the category of harm resulting from AEs (Table 3), we found the presence of harm during hospitalization in all categories, with a prevalence (47.8\%) of temporary harm, requiring prolonged hospitalization (category F). AEs identified at admission fell under the categories $\mathrm{E}$ and $\mathrm{F}$.

Table 3

Distribution of AEs according to the category of harm occurring during bospitalization and interrater agreement value

\begin{tabular}{ccccc}
\hline Category & $n(\%)$ of AEs during hospitalization & Kappa value & $n(\%)$ of AEs at admission & Kappa value \\
\hline E & $33(33.3 \%)$ & .862 & $19(17.8 \%)$ & .992 \\
F & $59(47.8 \%)$ & .887 & $6(6.7 \%)$ & 1.000 \\
G & $9(8.9 \%)$ & .935 & 0 & - \\
H & $15(14.4 \%)$ & .841 & 0 & - \\
I & $8(8.9 \%)$ & .935 & 0 & - \\
\hline
\end{tabular}

The number of harm per 1,000 patient days, the number of harm per 100 admissions and the rate of hospitalizations in which only one AE occurred was also calculated. We found a total of 62.63 AEs per 1,000 patient days, 137.8 AEs per 100 admissions, i.e. there is more than $1 \mathrm{AE}$ in each admission. In 31.1\% of the cases, there was an $\mathrm{AE}$ during hospitalization.

Pearson's correlation coefficient $(r-p)$ revealed a significant positive and strong correlation $(r-p=$ $.669 ; p=.001$ ) between the total length of stay and the number of AEs, indicating that patients hospitalized for more than 22 days suffered more AEs than other patients hospitalized for a shorter period of time.

We also aimed to check if the AEs occurring during hospitalization are influenced by age. Based on the obtained data $(r-p=.188 ; p=.076)$, we can confirm that there is no statistically significant correlation between these two variables, i.e. the AEs are not associated with the patient's age.

\section{Discussion}

This study allowed us to identify the rate of AEs in a medicine ward using the GTT during a 9-month period. The rate of AE occurrence was of $44.6 \%$ during hospitalization and of $9.4 \%$ at admission. The level of interrater agreement, calculated using the Kappa 
value, was considered as perfect, according to the classification of Landis and Koch (1977). This level of interrater agreement is, probably, related to the fact that the reviewers received, at the same time, training on the revision of clinical records using this methodology. In Thailand, Asavaroengchai, Sriratanaban, Hiransuthikul, and Supachutikul (2009) identified AEs in a tertiary hospital in Bangkok, using the GTT, and found a perfect (.86) level of interrater agreement, also calculated using the Kappa value.

Concerning the rate of AEs, the results found in our study are higher than those found in other studies: Landrigan et al. (2010), Rutberg et al. (2014), Rozenfeld, Giordani, and Coelho (2013), and Von Plessen, Kodal, and Anhoj (2012), obtained a mean rate of AEs during hospitalization, with minimum and maximum values ranging between 20.5\% and 25\%. With regard to the rate of AEs at admission, Rutberg et al. (2014) mention a rate of $5.1 \%$, whereas Landrigan et al. (2010) emphasize that $40 \%$ of the total of AEs occurred at admission.

As regards the number of AEs per 1,000 patient days, the results found in our study (62.63 AEs per 1,000 patient days) are closer to those obtained by Landrigan et al. (2010), with 56.6 AEs per 1,000 patient days. Classen et al. (2011) reported a higher rate of 91 AEs per 1,000 patient days. However, Rutberg et al. (2014) and Hwang et al. (2014) only obtained 33.2 and 7.39 AEs per 1,000 patient days, respectively.

The number of AEs reported per 100 admissions (137.8 AEs per 100 admissions) substantially exceeded those found in the literature analyzed, namely the rate of 49 AEs per 100 admissions found by Classen et al. (2011), the rate of 25.1 AEs per 100 admissions found by Landrigan et al. (2010), and the rate of $14.5 \mathrm{AEs}$ per 100 admissions found by Hwang et al. (2014).

Although the rate of AEs found in this study (31.1\%) is slightly lower than that found by Classen et al. (2011), 33.3\%, it is higher than the rates reported by Landrigan et al. (2010), 18.1\%, Hwang et al. (2014), 7\%, and Rutberg et al. (2014), 20.5\%.

The significant differences found between the results from the various studies could have been influenced by several factors, such as the organizational structure, the hospital's safety culture, the type of inpatients, the context where the study was carried out, the review process, and the reviewers' training.

The data found are of extreme importance, since the highest results identified in this study, when compared to other studies, call our attention to the urgent need to intervene in patient safety in this ward. In this study, when we analyzed the AEs per category of harm, we found it interesting that temporary harm requiring intervention and acquired during hospitalization was less common than temporary harm requiring prolonged hospitalization, and that the harm requiring intervention necessary to sustain life was more common than permanent harm.

Classen et al. (2011) identified a higher number of AEs with harm requiring intervention necessary to sustain life (nosocomial infections and procedure complications) than AEs with temporary harm requiring prolonged hospitalization (medication). Patient's death was related to thromboembolism.

It is important to note that, in our study, the AEs with temporary harm requiring prolonged hospitalization prevailed due to the high number of readmissions within 30 days, the healthcare-associated infections and any procedure complications. We found that the high number of readmissions within 30 days was associated with early discharges. In addition, the AEs with harm contributing to the patient's death also drew our attention $(n=6)$, with four of these cases being related to aspiration pneumonia and two with septicemia.

Some relevant limitations were identified in this study. One of them relates to the fact that this methodology was applied in a single medical ward and that, due to the inpatients' profile, most triggers belonged to the module of general care and medication. In addition, the patients' clinical information in the clinical records proved to be scarce, which made it difficult to classify the AEs occurring during hospitalization, as well as to identify the time elapsed Between $\mathrm{AE}$ and readmission. Finally, another limitation was the shortage of international studies on this issue, which hampered the comparison of our findings. To date, we are not aware of any other studies carried out in Portugal aimed at assessing AEs in hospitals using this methodology, which prevented us from comparing our data to other Portuguese realities.

\section{Conclusion}

Today, the need to introduce new methodologies with the purpose of studying AEs in Portuguese hospitals has become a key factor. This study identified the 
occurrence of AEs in a medical ward of a hospital unit in Portugal through the GTT methodology.

When analyzing the relationship between the total length of stay and the number of AEs, we found that the patients hospitalized for more than 22 days had a higher number of AEs, i.e. the severity of AEs is associated with an increased hospital length-of-stay. Despite this, the AEs do not depend on the patient's age.

In fact, the GTT methodology allowed us to identify the rate of AEs occurring in a medical ward, as well as to identify and classify the AEs per category of harm. Based on the collected data, we found a significant number of AEs in this ward, namely resulting in the prolonged hospitalization and patient's death. The events related to a longer length of stay prevailed due to the high number of readmissions within 30 days, the healthcare-associated infections and any procedure compliaction. Aspiration pneumonia was the main cause of death among patients.

The obtained results reflect the real dimension and magnitude of the problem at an institutional level. In order to know the real extent of this issue, other Portuguese institutions must conduct studies of this nature aimed at identifying AEs through the application of the GTT methodology.

These results can guide the development of other studies with the purpose of analyzing the causes of AEs in Portugal and, subsequently, calling the attention to the development of strategies to address this important issue related to care quality and patient safety.

\section{Referências bibliográficas}

Asavaroengchai, S., Sriratanaban, J., Hiransuthikul, N., \& Supachutikul, A. (2009). Identifying adverse events in hospitalized patients using Global Trigger Tool in Thailand. Asian Biomedicine, 3(5), 545-550. Retrieved from http:// www.asianbiomed.org/htdocs/previous/A20093545.pdf

Classen, D. C. (2009). Challenges in implementation of Trigger and TIDS tools for detection of adverse events in health care settings. In Agency for Healthcare Research and Quality (Ed.), Triggers and Targeted Injury Detection Systems (TIDS) expert panel meeting: Conference summary, Rockville, MD, 30 June-1 July 2008 (pp. 29-30). Retrieved from http:// archive.ahrq.gov/news/events/other/triggers/triggers.pdf
Classen, D. C., Resar, R., Griffin, F., Federico, F., Frankel, T., Kimmel, N., ... James, B. C. (2011). "Global trigger tool" shows that adverse events in hospitals may be ten times greater than previously measured. Health Affairs (Project Hope), 30(4), 581-589. doi: 10.1377/hlthaff.2011.0190

Despacho no ${ }^{0}$ 1400-A/2015 de 10 de fevereiro. Diário da República $n^{\circ}$ 28/2015, $1^{\circ}$ Supl. - $2^{a}$ Série. Ministério da Saúde, Gabinete do Secretário de Estado Adjunto do Ministro da Saúde. Lisboa, Portugal.

Direcção-Geral da Saúde. (2011). Estrutura concetual da classificação internacional sobre segurança do doente: Relatório técnico final. Retrieved from https://www.dgs. $\mathrm{pt} /$ documentos-e-publicacoes/classificacao-internacionalsobre-seguranca-do-doente-png.aspx

Direcção-Geral da Saúde. (2014). Sistema Nacional de Notificação de Incidentes: NOTIFICA (Norma n ${ }^{0}$ 015/2014 de 25/09/2014). Retrieved from https://www.dgs.pt/paginasde-sistema/saude-de-a-a-z/notificacao-de-incidentes-eeventos-adversos.aspx

Ganachari, M. S., Wadhwa, T., Walli, S., Khoda, D. A., \& Aggarwal, A. (2013). Trigger tools for monitoring and reporting of adverse drug reactions: A scientific tool for efficient reporting. Open Access Scientific Reports, 2(4), 2-6. doi: $10.4172 /$ scientificreports

Hwang, J.-I., Chin, H. J., \& Chang, Y.-S. (2014). Characteristics associated with the occurrence of adverse events: A retrospective medical record review using the Global Trigger Tool in a fully digitalized tertiary teaching hospital in Korea. Journal of Evaluation in Clinical Practice, 20(1), 27-35. doi: 10.1111/jep.12075

Improvement, I. for H. (2009). IHI Global Trigger Tool for measuring adverse events. Innovation. Institute for Healthcare Improvement. Retrieved from www.IHI.org

Landis, J. R., \& Koch, G. G. (1977). The measurement of observer agreement for categorical data. Biometrics, 33(1), 159-174. doi: $10.2307 / 2529310$

Landrigan, C. P., Parry, G. J., Bones, C. B., Hackbarth, A. D., Goldmann, D. A., \& Sharek, P. J. (2010). Temporal trends in rates of patient harm resulting from medical care. The New England Journal of Medicine, 363(22), 2124-2134. doi: 10.1056/NEJMsa1004404

Murff, H. J., Patel, V. L., Hripcsak, G., \& Bates, D. W. (2003). Detecting adverse events for patient safety research: A review of current methodologies. Journal of Biomedical Informatics, 36(1-2), 131-143. doi: 10.1016/j.jbi.2003.08.003

Observatório Português dos Sistemas de Saúde. (2015). Acesso aos cuidados de saúde: Um direito em risco?: Relatório de primavera 2015. Retrieved from http://www.opss.pt/sites/ opss.pt/files/RelatorioPrimavera2015.pdf 
Pfeiffer, Y., Manser, T., \& Wehner, T. (2010). Conceptualising barriers to incident reporting: A psychological framework. Quality \& Safety in Health Care, 19(6), e60. doi: 10.1136/ qshc.2008.030445

Rosen, A. K., \& Mull, H. J. (2016). Identifying adverse events after outpatient surgery: improving measurement of patient safety. BMJ Quality \& Safety, BMJ Quality \& Safety, 25, 3-5. doi: 10.1136/bmjqs-2015-004752

Rozenfeld, S., Giordani, F., \& Coelho, S. (2013). Eventos adversos a medicamentos em hospital terciario: Estudo piloto com rastreadores. Revista de Saúde Pública, 47(6), 1102-1111. doi: 10.1590/S0034-8910.2013047004735

Rutberg, H., Borgstedt Risberg, M., Sjödahl, R., Nordqvist, P., Valter, L., \& Nilsson, L. (2014). Characterisations of adverse events detected in a university hospital: A 4-year study using the Global Trigger Tool method. BMJ Open, 4(5), e004879. doi: 10.1136/bmjopen-2014-004879

Sousa, P., Uva, A. S., Serranheira, F., Leite, E., \& Nunes, C. (2011). Segurança do doente: Eventos adversos em hospitais portugueses: Estudo piloto de incidência, impacte e evitabilidade. Retrieved from https://www.ensp.unl.pt/ invest-desenvolv-inov/projectos/brochura_estudo_ea2011. pdf

Tingle, J. (2011). The WHO patient safety curriculum guide. Br J Nurs, 20, 1456-7. doi:10.1097/00001888-200005000-000822

Von Plessen, C., Kodal, A. M., \& Anhoj, J. (2012). Experiences with global trigger tool reviews in five Danish hospitals: An implementation study. BMJ Open, 2(5), 1-8. doi: 10.1136/ bmjopen-2012-001324 
